\title{
Predictive factors for beneficial application of high-frequency electromagnetics for tumour vaporization and coagulation in
} neurosurgery

\author{
Rainer Ritz ${ }^{1}$, Stefan Heckl1 ${ }^{1}$ Sam Safavi-Abbasi², Guenther C Feigl1, \\ Boris Krischek ${ }^{1}$, Wolf Lüdemannn ${ }^{2}$, Javed M Mirzayan ${ }^{2}$, Andrei Koerbel ${ }^{1}$, \\ Madjid Samii ${ }^{2}$, Marcos Tatagiba ${ }^{1}$ and Alireza Gharabaghi*1
}

\begin{abstract}
Address: ${ }^{1}$ Department of Neurosurgery, Eberhard Karls University, Tübingen, Germany and ${ }^{2}$ Neurosurgery, International Neuroscience Institute, Hannover, Germany

Email: Rainer Ritz - not@valid.com; Stefan Heckl - not@valid.com; Sam Safavi-Abbasi - not@valid.com; Guenther C Feigl - not@valid.com; Boris Krischek - not@valid.com; Wolf Lüdemann - not@valid.com; Javed M Mirzayan - not@valid.com; Andrei Koerbel - not@valid.com; Madjid Samii -not@valid.com; Marcos Tatagiba - not@valid.com; Alireza Gharabaghi* - alireza.gharabaghi@uni-tuebingen.de

* Corresponding author
\end{abstract}

World Journal of Surgical Oncology 2008, 6:45 doi:10.1/86/1477-78/9-6-45

This article is available from: http://www.wjso.com/content/6/l/45

(C) 2008 Ritz et al; licensee BioMed Central Ltd.

This is an Open Access article distributed under the terms of the Creative Commons Attribution License (http://creativecommons.org/licenses/by/2.0), which permits unrestricted use, distribution, and reproduction in any medium, provided the original work is properly cited.

\begin{abstract}
Objective: To identify preoperative and intraoperative factors and conditions that predicts the beneficial application of a high-frequency electromagnetic field (EMF) system for tumor vaporization and coagulation.
\end{abstract}

Methods: One hundred three subsequent patients with brain tumors were microsurgically treated using the EMF system in addition to the standard neurosurgical instrumentarium. A multivariate analysis was performed regarding the usefulness (ineffective/useful/very helpful/essential) of the new technology for tumor vaporization and coagulation, with respect to tumor histology and location, tissue consistency and texture, patients' age and sex.

Results: The EMF system could be used effectively during tumor surgery in 83 cases with an essential contribution to the overall success in 14 cases. In the advanced category of effectiveness (very helpful/essential), there was a significant difference between hard and soft tissue consistency (50 of 66 cases vs. 3 of 37 cases). The coagulation function worked well (very helpful/essential) for surface (73 of 103 cases) and spot (46 of 103 cases) coagulation when vessels with a diameter of less than one millimeter were involved. The light-weight bayonet hand piece and long malleable electrodes made the system especially suited for the resection of deep-seated lesions (34 of 52 cases) compared to superficial tumors ( 19 of 50 cases).

The EMF system was less effective than traditional electrosurgical devices in reducing soft glial tumors. Standard methods where also required for coagulation of larger vessels.

Conclusion: It is possible to identify factors and conditions that predict a beneficial application of high-frequency electromagnetics for tumor vaporization and coagulation. This allows focusing the use of this technology on selective indications. 


\section{Background}

A wide range of electrosurgical devices has been developed during the last decades to facilitate tumor removal and/or hemostasis in surgery [1-6]. As most of these electrosurgical instruments are based on unique principles, they have to be carefully evaluated with respect to the possibility of added functionality and efficacy as a surgical adjunct [4,7-11].

Recently, the clinical applicability of a new commercially available, high-frequency electromagnetic field (EMF) system has been demonstrated [12], and specific handling techniques and electrode tip configurations could be defined for optimal use [13].

However, there is still the necessity for a systematic evaluation of benefits and shortcomings of this radiofrequency electrosurgical unit in order to define its place in the standard surgical armamentarium for tumor resection. Therefore, this study was performed to identify preoperative and intraoperative factors and conditions that predict the beneficial application of this system in tumor vaporization and coagulation during brain surgery.

\section{Methods}

\section{Patient Population}

One hundred three subsequent patients with intracranial tumours including 38 meningiomas, 23 neurinomas, 19 gliomas, 12 metastasis, 5 adenocarcinomas, 4 chordomas, and 2 adenomas were treated surgically with the aid of the EMF system.

\section{Description of the EMF system}

The system to be evaluated (Orion- $1^{\mathrm{TM}}$ EMF System, Ortho Development Corp., Salt Lake City, Utah, USA) is an electrosurgical device operating at radiofrequency (13.56 $\mathrm{MHz}$ ) with a maximum electrical output of 16 watts. [3] Based on the principles of electromagnetics, the system generates localized heat when the tips of the electrodes interact with underlying living tissue. Its functions are defined as vaporization, cutting, and coagulation controlled by depressing one of two foot pedals labeled "vapo/ cut" and "coagulation", respectively. The system offers two disposable handpiece types (bayonet and straight) with disposable electrodes featuring six different electrode tips ( 1 and $2 \mathrm{~mm}$ ball, 3 and $5 \mathrm{~mm}$ ring, needle, and blade). The ball and ring tips are malleable. The electrode shafts are supplied in a long $(95-100 \mathrm{~mm})$ and in a short (55-60 mm) version.

\section{Evaluation of the EMF system}

All microsurgical approaches were performed without modification of the surgical strategy for the purpose of this study; the EMF System was used as an adjunct or, at times, as a substitute for other instruments.
In each case, the whole range of EMF functionality was evaluated during surgery by interviewing the surgeon immediately after each maneuver. Thereby, all options (vaporization, cutting, and coagulation) have been explored in each case in the course of the study. Moreover, the coagulation mode was evaluated separately for surface bleeding, small vessels, and large vessels.

Immediately after operation, the surgeon rated the overall performance of the system in terms of effectiveness (ineffective vs. effective) and graded - in cases of effective application - its contribution to the surgical procedure (useful, very helpful, or essential). Thereafter, we performed a multivariate analysis including tumor histology and location, tissue consistency and texture, patients' age and sex. Statistical evaluation included Student's t test with paired and unpaired comparisons and Fisher's exact test. $P$ values less that 0.05 were considered significant.

\section{Results}

The EMF system functioned properly in all 103 procedures and was not attributed to any complications. It could be used effectively during surgery in 83 of 103 cases, being useful, very helpful, and essential in 30,39, and 14 cases, respectively (Fig. 1). Patients' age and sex did not correlate to any of the analyzed categories.

Sixty-six of all 103 lesions were classified as tumors with a hard consistency by the treating neurosurgeon. In 50 of these 66 cases, the contribution of the EMF system to the overall success was rated as very helpful or essential. In the group of tumors with a soft tissue consistency, there were only 3 of 37 cases in the same category of effectiveness (very helpful or essential) (Fig. 2). This difference between

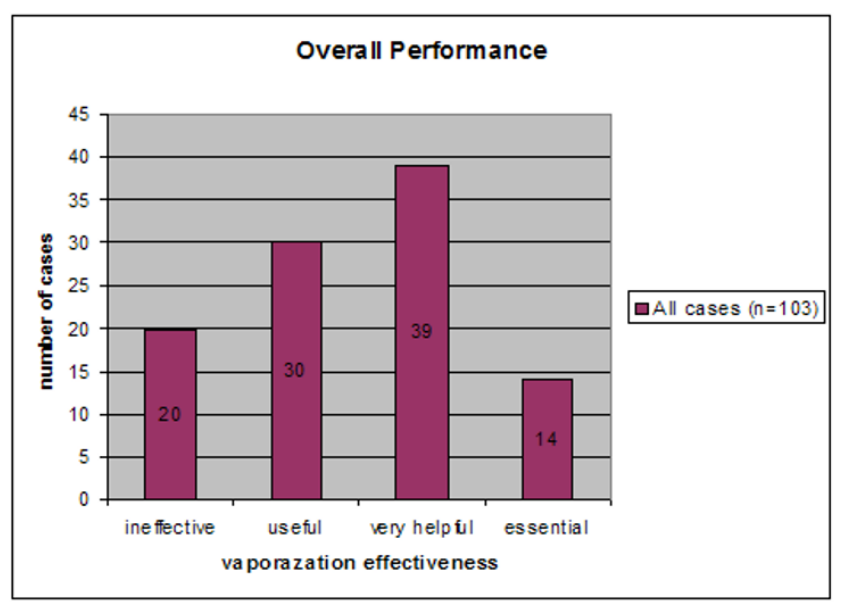

\section{Figure I}

Overall EMF vaporization effectiveness (ineffective/useful/ very helpful/essential) in 103 brain tumour cases. 


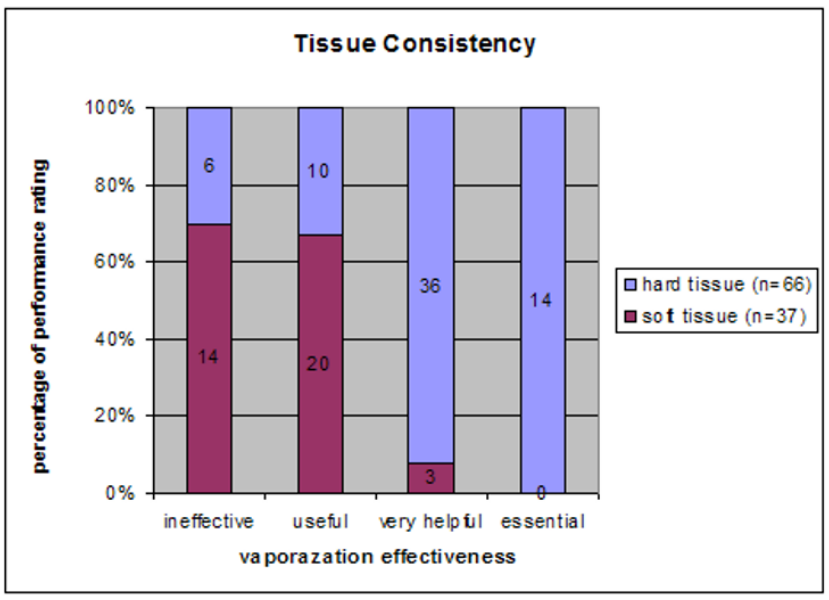

Figure 2

EMF vaporization effectiveness (ineffective/useful/very helpful/essential) comparing different tumour consistencies (hard/ soft).

hard and soft tissue consistency in terms of effective EMF application was significant $(\mathrm{p}<0.05)$.

Fifty-three of all 103 lesions were classified as deep-seated tumors. In 34 of these 53 cases, the contribution of the EMF system to the overall success was rated as very helpful or essential. In the group of tumors located at the surface, there were 19 of 50 cases in the same category of effectiveness (very helpful or essential) (Fig. 3). This difference between deep-seated and surface tumors in terms of effective EMF application was significant $(\mathrm{p}<0.05)$.

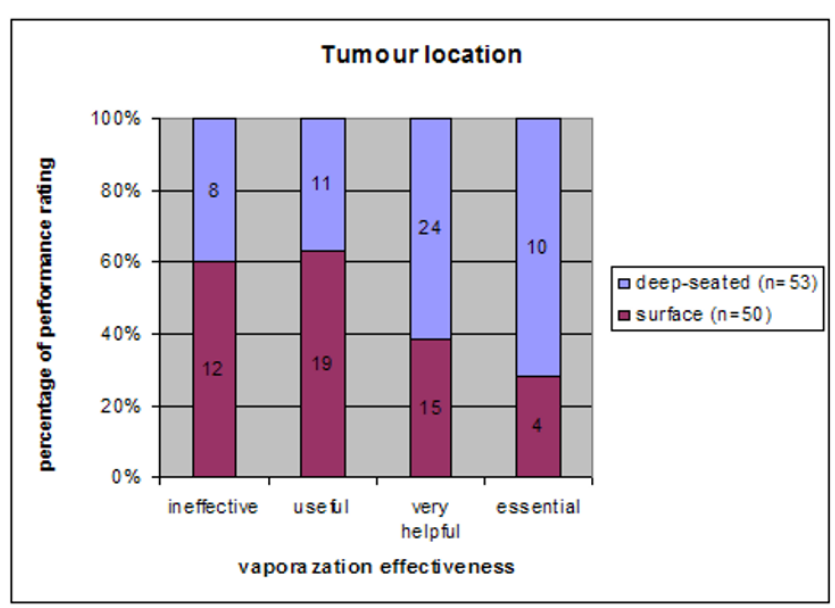

\section{Figure 3}

EMF vaporization effectiveness (ineffective/useful/very helpful/essential) comparing different tumour locations (deepseated/surface).

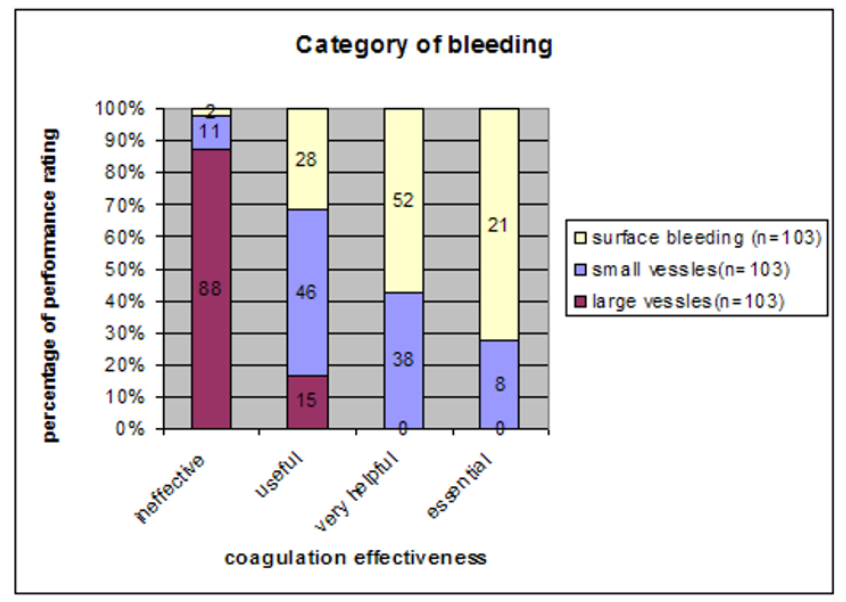

\section{Figure 4}

EMF coagulation effectiveness (ineffective/useful/very helpful/ essential) comparing different bleeding categories (surface/ small vessels/large vessels).

The coagulation function worked well (very helpful/ essential) for surface ( 73 of 103 cases) and spot (46 of 103 cases) coagulation when vessels with a diameter of less than one millimeter were involved. In large vessels the EMF system was ineffective in 88 of 103 cases and was considered useful in only 15 of 103 cases (Fig. 4). This difference in terms of effectiveness regarding coagulation of larger vessels was significant $(\mathrm{p}<0.05)$.

\section{Discussion}

The effectiveness of the vaporizing function of the EMF system was directly affected by the location of the surgical field and the type of tissue involved.

The ergonomic design of the handpiece combined with a very light weight allowed for comfortable handling while operating on deep-seated lesions. The bayonet shape was completely compatible with the microscope and did not block the surgical view. When used in conjunction with the long malleable electrodes, the EMF system was found to be especially suited for long approaches to deep-seated lesions as both access and visibility were improved compared to surgery employing the shorter and more voluminous ultrasound aspirator. The ability to use a singletipped probe on tumors compressing the brain stem through narrow approaches without adverse affects caused by heat or current undoubtedly adds to the standard surgical armamentarium.

Recent findings indicate that electromagnetic field and local inductive hyperthermia have an impact on tumor growth [14]. Though, it has to be emphasized that there is a difference between radiofrequency hyperthermia producing heating of a whole tumor, and an electromagnetic 
devise which is used for surgical tumor resection by creating pinpoint heat at the probe tip. This focused effect is induced in the present study by applying a sharp convergence of the current with maximum current density at the probe tip, resulting in minimal spread of heat, and the capability to vaporize tissue in a very focal way $[5,12,15,16]$.

The EMF system performed best in harder tumors. With rubbery or fibrous tumors the electrodes did not have difficulty cutting through the tissue for dissection. However, the device was not effective for resection of highly calcified tumors. In future a preoperative computed tomography may help to avoid unnecessary application of the system in calcifies lesions.

Moreover, the EMF system was less effective than traditional electrosurgical devices in reducing soft glial tumors. In soft or cystic tumors, the system's electrodes would become enveloped in tumor and the thermal reaction would be stifled. Therefore, at our institutions the EMF systems are not any longer used for glial tumors.

When the ball tips where used together with the coagulation mode, surface coagulation was possible and proved most effective. The coagulation mode could also be used for cutting purpose with ring, needle and blade tip electrodes. When working in vascular tissue it was possible to use the coagulation mode for a cut with a surrounding peripheral zone of coagulation in a number of cases. Thus an incision could be made without the need to switch tools.

In large vessels the EMF system was not effective. In these cases, standard methods where required for coagulation. In highly vascularized tumors, the effectiveness of the EMF System was also greatly hampered. In these cases, bipolar coagulation had to be used predominantly.

The necessity to switch to an ultrasonic aspirator when resecting soft tumor tissue or to a bipolar forceps when coagulating larger vessels may present as a major drawback of the present EMF system. Therefore, at present electrosurgical units based on electromagnetic fields are not able to replace the standard devised, but may serve as a valuable tool in specific indications.

\section{Conclusion}

This new electrosurgical device adds to the armamentarium for the resection of hard and fibrous tumors especially in small approaches to deep-seated lesions. The coagulation function worked better for surface and spot coagulation when vessels with a diameter of less than one millimeter were involved. A thorough understanding of the indications and principles of the new technique is required for its effective use. It has the potential to attain a place as a complementary tool with additional functionality among the standard surgical equipment.

\section{Competing interests}

The authors declare that they have no competing interests.

\section{Authors' contributions}

RR and AG conceived of the study, implemented the technology, and participated in its design and coordination and drafted the manuscript. MS and MT participated in the coordination of the study and helped to draft the manuscript. SH, SSA and GCF participated in the design of the study and performed the statistical analysis. BK, WL, MJM and AK carried out the surgical application of the EMF tool, participated in the tumour and vessel categorizations, as well as in the postoperative interviews. All authors read and approved the final manuscript.

\section{Acknowledgements}

We would like to thank Jesse D'Alessio for his technical support and excellent assistance throughout the study.

\section{References}

I. Cushing $\mathrm{H}$ : Electro-surgery as an aid to the removal of intracranial tumours. Surg Gynecol Obstet 1928, 47:751-784.

2. Greenwood J Jr: Two point coagulation. A new principle and instrument for applying coagulation current in neurosurgery. Am J Surg 1940, 50:267-270.

3. Malis LI: Bipolar coagulation in microsurgery. In Micro-Vascular Surgery Edited by: Donaghy RMP, Yasargil MG. Stuttgart: Thieme; 1967:126-130.

4. Abe T, Tanioka D, Sugiyama K, Kawano M, Murakami K, Izumiyama $\mathrm{H}$ : Electromagnetic field system for trassphenoidal surgery on recurrent pituitary lesions-technical note. Surg Neurol 2007, 67:40-45.

5. Patil AA, Yamanashi WS, Valentine JL, Hill D: Electromagnetic field focusing system in the treatment of brain tumours. Neurosurgery 1988, 22:18-22.

6. Patil AA, Yamanashi W: Electroconvergent cautery. Neurosurgery 1994, 35(4):785-7.

7. Chehrazi B, Collins WF Jr: A comparison of effects of bipolar and monopolar electrocoagulation in brain. J Neurosurg 198I, 54:197-203.

8. Greenwood J Jr: Two point or interpolar coagulation. Review after a twelve-year period with notes on addition of a sucker tip. J Neurosurg 1955, I 2:196-197.

9. Hashimoto T, Patil AA, Yamanashi W, et al.: Usefulness of electromagnetic field (EMF) system in skull base and deep seated brain tumors. In Proceedings of I I th European Congress of Neurosurgery Bologna, Italy: Monduzzi; 1999:40 I-406.

10. Malis LI: New trends in microsurgery and applied technology. In Advanced Technology in Neurosurgery Edited by: Pluchino F, Broggi G. Berlin: Springer-Verlag; 1988: I-16.

II. Malis LI: Electrosurgery. J Neurosurg 1996, 85:970-975.

12. Gharabaghi A, Rosahl SK, Samii A, Feigl GC, Safavi-Abbasi S, Bundschuh O, Tatagiba M, Samii M: Applicability of an electrosurgical device based on electromagnetics in neurosurgery. Neurosurgery 2006, 59(I Suppl):ONSI42-5.

13. Gharabaghi A, Safavi-Abbasi MD, Krischek B, Feigl GC, Lüdemann W, Mirzayan MJ, Samii M, Tatagiba M, Heckl S: The use of high-frequency electromagnetics in brain tumour surgery. Eur J Surg Oncol in press. Oct 22, 2007

14. Orel VE, Dzyatkovskaya NN, Romanov AV, Kozarenko TM: The effect of electromagnetic field and local inductive hyperthermia on nonlinearmdynamics of the growth of transplanted animal tumors. Exp Oncol 2007, 29(2): I56-I58. 
15. Yamanashi WS, Patil AA, Hill DL, Lepage JR, Yassa NA, Valentine JL, Lester PD: Precision surgery with an electromagnetically induced current convergence probe application in aneurysm treatment, angioplasty, and brain tumor resection in in vivo and in vitro models. Med Instrum 1988, 22:205-216.

16. Yamanashi WS, Hudkin B, Dempewolf S, Patil AA, Clingan FA, McGee JM: Thermal profiles of electrocauteries, the Nd:YAG laser, and the electromagnetic-field focusing system. Biomed Instrum Technol 1992, 26:4I4-42I.

Publish with Bio Med Central and every scientist can read your work free of charge

"BioMed Central will be the most significant development for disseminating the results of biomedical research in our lifetime. " Sir Paul Nurse, Cancer Research UK

Your research papers will be:

- available free of charge to the entire biomedical community

- peer reviewed and published immediately upon acceptance

- cited in PubMed and archived on PubMed Central

- yours - you keep the copyright

Submit your manuscript here:

http://www.biomedcentral.com/info/publishing_adv.asp 